\title{
ORIGINAL
}

ARTICLES

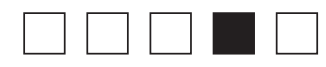

\section{Abortion Provision Among Recently Graduated Family Physicians}

Payal Patel, MD; Sumathi Narayana, MD, MS; Aleza Summit, MPH; Marji Gold, MD; Zachary J. Morgan, MS; Aimee R. Eden, PhD, MPH; Lars E. Peterson, MD, PhD; Allison Paul, MD, MPH

BACKGROUND AND OBJECTIVES: Family physicians (FPs) are well positioned to increase abortion access given their broad scope and diverse geographic practice regions. Previously published studies focus on physicians who received formal abortion training but do not include the full landscape of FPs performing abortions in the United States. This secondary data analysis presents a unique opportunity to examine characteristics of early-career FPs who provide abortions, including practice locations and if they received abortion training during residency.

METHODS: We analyzed data from the 2016-2018 Family Medicine National Graduate Survey to generate descriptive statistics about respondents who report providing pregnancy termination, uterine aspiration/dilation and curettage, or both. We evaluated associations between physician and/or practice characteristics and providing pregnancy termination using bivariate statistics.

RESULTS: Of the 6,319 survey respondents, $3 \%$ reported providing pregnancy termination. Nearly three-quarters of this subset reported graduating residency feeling prepared to provide pregnancy termination. Most respondents completed residency in the West or Northeast US geographic regions, and $\mathbf{3}$ years later were practicing in the West or South regions. Additional characteristics associated with providing pregnancy termination include female gender, providing continuity care, and practicing in either an academic medical center or a federally qualified health center.

CONCLUSIONS: FPs are well positioned to address gaps in abortion access, and those who provide pregnancy termination practice in various US geographic regions. This is the first discussion of its kind about the scope of family physicians providing abortion care. Future research should continue to characterize FPs who provide abortions to determine where they train and practice and what type of abortions they provide.

(Fam Med. 2020;52(10):724-9.)

doi: 10.22454/FamMed.2020.300682

[ arly abortion care is extremely safe and one of the most common procedures in the United States. ${ }^{1}$ Abortion is most commonly performed in the first trimester, accounting for approximately $91 \%$ of all abortions in the United States. ${ }^{2}$
However, for patients nationwide, access to early abortion care remains difficult, often due to legal restrictions and uneven distribution of clinicians. A 2018 study identified 27 "abortion deserts," within the United States, defined as areas in which people would have to travel more than 100 miles to reach an abortion provider. $^{3}$ Furthermore, $38 \%$ of reproductive-aged women live in counties with no abortion provider at all. ${ }^{2}$

Family physicians (FP's) are well poised to fill these gaps and to provide this crucial service in areas where abortion access is limited. Workforce data show that FPs are the most common medical specialty practicing in areas of the United States with the largest barriers to abortion care. ${ }^{4-7}$ Additionally, abortion care is well within the FPs scope of practice. Evidence from the 2018 National Academies of Sciences, Engineering, and Medicine consensus report about abortion care in the United States showed that FPs can provide abortions safely and effectively in the outpatient setting. ${ }^{2}$ Early abortion care draws upon skills that are already core components of family medicine, such as counseling, pregnancy diagnosis, determination of gestational age, procedural skills, and medication management. Moreover, a 2013 cross-sectional survey of a nationally representative sample

From the Department of Family and Social Medicine, Albert Einstein College of Medicine/ Montefiore Medical Center, Bronx, NY (Drs Patel, Narayana, Gold, and Paul); Reproductive Health Education in Family Medicine, Bronx, NY (Dr Gold and Ms Summit); American Board of Family Medicine, Lexington, KY (Drs Eden and Peterson, and Mr Morgan); and Department of Family and Community Medicine, College of Medicine, University of Kentucky, Lexington, KY (Dr Peterson). 
of family medicine educators found that $73 \%$ of respondents agreed abortion was within their scope of practice, and that $88 \%$ had treated early pregnancy loss. While these findings seem to support abortion provision in the primary care setting, only $15.3 \%$ of survey respondents were offering early abortion care. ${ }^{8}$ This discrepancy is partially explained by the fact that only $7 \%$ of family medicine residency programs include routine training in early abortion care. ${ }^{9}$

Several studies have demonstrated how particular aspects of receiving abortion care within the primary care setting are acceptable to patients, and, in some cases, preferable. Research focusing on patients' perspectives has illustrated how the integration of abortion into routine primary care allows patients to avoid potential harm caused by security measures, protesters, and the social stigma associated with receiving this care in an abortion clinic. ${ }^{10-20}$

To date, the vast majority of available medical literature about abortion providers has focused on $\mathrm{OB} /$ GYNs. All of the available medical literature that includes FPs are limited to those who completed residency programs committed to providing abortion training. ${ }^{21-25}$ Little is known about the population of FPs who are providing abortion care across the country. Analysis of data from the first 3 years of the National Graduate Survey, a collaborative effort between the American Board of Family Medicine (ABFM) and the Association of Family Medicine Residency Directors (AFMRD), offers a new opportunity to learn about the characteristics and distribution of FPs who are providing abortion care.

\section{Methods}

We analyzed data from the 2016, 2017, and 2018 National Graduate Surveys. The National Graduate Survey is administered to ABFM diplomates 3 years after residency graduation (ie, 2013 graduates were surveyed in 2016), and results are reported back to program directors to provide outcomes of training. The survey has achieved a high response rate $(67 \%)$ from a representative sample. ${ }^{26}$ Survey content was created with broad input from the family medicine educator community and covers topics including preparation for practice, actual practice, practice organization and location, and satisfaction with training. ${ }^{27} \mathrm{ABFM}$ administrative data contains basic demographics such as age, gender, and degree type.

Main variables of interest in this analysis were whether FPs felt residency training prepared them to provide abortions, and whether they were providing abortion care. The survey instrument used the term "pregnancy termination," to denote abortion. This question was one of 25 scope of practice items listed as paired questions about both residency preparedness and current practice. The survey also collected data on whether respondents provided the following sexual and reproductive health (SRH) procedures: long acting reversal contraception (LARC), including insertion and removal of intrauterine devices (IUDs) and implantable contraceptives; endometrial biopsy; maternity care; uterine aspiration/dilation and curettage (D\&C); colposcopy; and attending deliveries (referred to as "delivering babies" in the survey instrument). Respondents selected one of many practice settings to describe their principle practice site. During secondary data analysis, the authors preserved the following categories: hospital/health system owned medical practice, independently-owned medical practice, academic medical center, and federally qualified health center (FQHC) from the original survey instrument. All other practice site categories, (work clinic, federal, government clinic [nonfederal], Indian Health Service, rural health clinic (federally qualified), managed care/ HMO practice, and other) were collapsed into "other practice setting." The data were also categorized by both the practice state and training state by US Census Regions.
The sample was restricted to those who self-identified as providing direct patient care. We used bivariate statistics to determine associations between physician and practice characteristics and providing pregnancy termination. We also examined associations between feeling prepared to provide and actual provision of pregnancy termination, as well as associations between providing pregnancy termination and providing uterine aspiration. We assessed the association between providing pregnancy termination and providing other SRH procedures. We conducted all analyses in SAS v 9.2 (Cary, NC). The American Academy of Family Physicians Institutional Review Board approved this study.

\section{Results}

During 2016 to 2018, the Graduate Survey was offered to 9,669 ABFM diplomates and 6,483 (67.0\%) responded. Respondents not in direct patient care and those who reside outside the contiguous United States or who did not provide primary care in their principal practice state were excluded from analysis, leaving 6,319 respondents. Given that not all respondents answered every question, and some questions allowed respondents to provide open text responses (including their current state of practice), denominators vary by question.

Of the sample, only 189 physicians (3\%) indicated they provided pregnancy terminations. Of the participants who provide pregnancy termination, the median age was 35 years, and most were female $(70 \%$, Table 1). A vast majority (87\%) of respondents who provided pregnancy termination also provided continuity care and did so most commonly in academic medical centers (28\%) and FQHCs (24\%).

Of the respondents who provide pregnancy termination, $73 \%$ felt prepared for providing pregnancy termination when they graduated residency. The fact that $26 \%$ of respondents reported not feeling prepared to provide pregnancy termination upon residency graduation, 
Table 1: Personal and Practice Characteristics of 2016 Through 2018 Respondents to the Family Medicine National Graduate Survey by Provision of Pregnancy Termination $(\mathrm{N}=6,319)$

\begin{tabular}{|c|c|c|c|c|}
\hline & $\begin{array}{c}\text { Provides } \\
\text { Pregnancy } \\
\text { Termination }\end{array}$ & $\begin{array}{c}\text { Does Not Provide } \\
\text { Pregnancy } \\
\text { Termination }\end{array}$ & Total & $P$ Value \\
\hline All Respondents & $\mathrm{N}=189, \mathbf{3 . 0} \%$ & $\mathrm{~N}=6,130,97.0 \%$ & $\mathrm{~N}=6,319$ & \\
\hline Age & & & & .119 \\
\hline Under 35 years & $94(49.7 \%)$ & $3,399(55.3 \%)$ & $3,493(55.4 \%)$ & \\
\hline 35 years or older & $95(50.3 \%)$ & $2,731(44.7 \%)$ & $2,826(44.6 \%)$ & \\
\hline Gender & & & & $<.001$ \\
\hline Male & $56(29.6 \%)$ & $2,707(44.2 \%)$ & $2,763(43.7 \%)$ & \\
\hline Female & $133(70.3 \%)$ & $3,423(55.8 \%)$ & $3,556(56.3 \%)$ & \\
\hline Provides Continuity Care & & & & .017 \\
\hline Yes & $166(87.8 \%)$ & $4,935(80.5 \%)$ & $5,101(80.7 \%)$ & \\
\hline No & $23(12.2 \%)$ & $1,195(19.5 \%)$ & $1,218(19.3 \%)$ & \\
\hline Regions of Residency Training & $\mathrm{N}=\mathbf{1 8 8}$ & $N=6,088$ & $\mathrm{~N}=6,276$ & $<.001$ \\
\hline West & $66(35.1 \%)$ & $1,333(21.8 \%)$ & $1,402(22.2 \%)$ & \\
\hline Midwest & $41(21.8 \%)$ & $1,690(27.7 \%)$ & $1,731(27.5 \%)$ & \\
\hline South & $33(17.5 \%)$ & $2,028(33.3 \%)$ & $2,062(32.8 \%)$ & \\
\hline Northeast & $48(25.5 \%)$ & $1,037(17.0 \%)$ & $1,085(17.2 \%)$ & \\
\hline Regions of Current Practice & $\mathrm{N}=\mathbf{1 8 2}$ & $N=5,949$ & $\mathrm{~N}=6,131$ & $<.001$ \\
\hline West & $76(41.7 \%)$ & $1,648(27.7 \%)$ & $1,724(28.0 \%)$ & \\
\hline Midwest & $34(18.7 \%)$ & $1,380(23.2 \%)$ & $1,414(23.1 \%)$ & \\
\hline South & $38(20.8 \%)$ & $2,136(35.9 \%)$ & $2,174(35.4 \%)$ & \\
\hline Northeast & $34(18.7 \%)$ & $785(13.2 \%)$ & $819(13.3 \%)$ & \\
\hline Primary Practice Setting & $\mathrm{N}=\mathbf{1 6 6}$ & $\mathrm{N}=4,934$ & $\mathrm{~N}=5,100$ & $<.001$ \\
\hline Hospital/health system owned medical practice & $31(18.7 \%)$ & $1,930(39.2 \%)$ & $1,961(38.4 \%)$ & \\
\hline Independently-owned medical practice & $19(11.4 \%)$ & $751(15.2 \%)$ & $770(15.1 \%)$ & \\
\hline Academic medical center & $47(28.3 \%)$ & $503(10.2 \%)$ & $550(10.1 \%)$ & \\
\hline Federally qualified health center & $41(24.7 \%)$ & $583(11.8 \%)$ & $624(12.2 \%)$ & \\
\hline Other practice setting & $28(16.8 \%)$ & $1,167(23.7 \%)$ & $1,195(23.4 \%)$ & \\
\hline
\end{tabular}

but were providing pregnancy termination at the time of the survey, suggests that these physicians received training in abortion care after residency (Table 2). ${ }^{28}$ Of 187 physicians who provide pregnancy termination, 111 (59\%) provided uterine aspirations. Of 294 physicians who provided uterine aspirations, only $38 \%$ provided pregnancy terminations (Table 3).

Physicians who provide pregnancy terminations were more likely to provide all SRH procedures, including
LARC insertions and removals, endometrial biopsy, maternity care, uterine aspiration, colposcopy, and attending deliveries $(P<.001$ for all services, Table 4). Additionally, FPs who provide pregnancy termination are also more likely than their peers to teach medical students ( $75.1 \%$ vs $54.7 \%$ ), residents ( $73 \%$ vs $39.69 \%$ ), and fellows (19\% vs $6.6 \%, P<.001$, Table 5).

\section{Discussion}

In this large national study of over 6,000 recent family medicine residency graduates, we found that only $3 \%$ provided abortion care. When compared with other recent graduates, abortion providers are more likely to identify as female, to provide primary care, and to work in an academic medical center or a FQHC. Furthermore, abortion providers are much more likely to teach medical students, residents, and fellows. Recent studies suggest that one of the 
Table 2: Felt Prepared to Provide Pregnancy Termination at Residency Graduation vs Providing Pregnancy Termination

\begin{tabular}{|l|c|c|c|c|}
\hline \multirow{2}{*}{} & \multicolumn{2}{|c|}{ Provides Pregnancy Termination } & \multirow{2}{*}{$\begin{array}{c}\text { Total } \\
(\mathbf{N}=6,290)\end{array}$} & N Value \\
\cline { 2 - 4 } & Yes $(\mathbf{n = 1 8 8})$ & No (n=6,102) & (18) \\
\hline Prepared for pregnancy termination & $138(73.4 \%)$ & $683(11.2 \%)$ & $823(13.1 \%)$ & $<.001$ \\
\hline Not prepared for pregnancy termination & $50(26.6 \%)$ & $5,419(88.8 \%)$ & $\begin{array}{c}5,490 \\
(86.9 \%)\end{array}$ \\
\hline
\end{tabular}

Table 3: Physicians Who Provide Pregnancy Termination vs Physicians Who Provide Uterine Aspiration

\begin{tabular}{|c|c|c|c|c|}
\hline & \multicolumn{2}{|c|}{ Provides Pregnancy Termination } & \multirow{2}{*}{ Total $(\mathrm{N}=6,288)$} & \multirow{2}{*}{$P$ Value } \\
\hline & Yes $(n=187)$ & No $(n=6,101)$ & & \\
\hline Provides uterine aspiration & $111(59.3 \%)$ & $183(3.0 \%)$ & $294(4.7 \%)$ & $<.001$ \\
\hline Does not provide uterine aspiration & $76(40.7 \%)$ & $5,918(97.0 \%)$ & $5,994(95.3 \%)$ & \\
\hline
\end{tabular}

Table 4: Other Sexual and Reproductive Care Provided by Family Physicians Who Provide Pregnancy Terminations

\begin{tabular}{|l|c|c|c|c|}
\hline \multirow{2}{*}{} & \multicolumn{2}{|c|}{ Provides Pregnancy Termination } & \multirow{2}{*}{ Total (N=6,319) } & \multirow{2}{*}{$\boldsymbol{P}$ Value } \\
\cline { 2 - 4 } & Yes (n=189) & No (n=6,130) & & \\
\hline IUD insertion and removal & $175(92.6 \%)$ & $2,403(39.2 \%)$ & $2,578(40.8 \%)$ & $<.001$ \\
\hline Implantable long-acting reversible contraception & $167(88.4 \%)$ & $2,284(37.3 \%)$ & $2,452(38.8 \%)$ & $<.0001$ \\
\hline Endometrial biopsy & $146(77.2 \%$ & $1,459(23.8 \%)$ & $1,605(25.4 \%)$ & $<.0001$ \\
\hline Maternity care & $134(70.9 \%)$ & $1,489(24.3 \%)$ & $1,623(25.7) \%$ & $<.0001$ \\
\hline Uterine aspiration & $111(59.4 \%)$ & $183(3.0 \%)$ & $294(4.6 \%)$ & $<.001$ \\
\hline Colposcopy & $90(47.6 \%)$ & $763(12.4 \%)$ & $853(13.5 \%)$ & $<.001$ \\
\hline Deliver babies & $91(48.1 \%)$ & $784(12.8 \%)$ & $875(13.8 \%)$ & $<.001$ \\
\hline
\end{tabular}

Abbreviation: IUD, intrauterine device.

Table 5: Teaching Presence of Physicians Who Provide Pregnancy Terminations

\begin{tabular}{|l|c|c|c|c|}
\hline \multirow{2}{*}{} & \multicolumn{2}{|c|}{ Provides Pregnancy Termination } & \multirow{2}{*}{ Total (N=6,299) } & \multirow{2}{*}{$\boldsymbol{P}$ Value } \\
\cline { 2 - 4 } & Yes (N=169) & No (N=6,130) & & \\
\hline Teach medical students & $142(75.1 \%)$ & $3,354(54.7 \%)$ & $3,496(55.5 \%)$ & $<.001$ \\
\hline Teach residents & $138(73.0 \%)$ & $2,433(39.7 \%)$ & $2,571(40.8 \%)$ & $<.001$ \\
\hline Teach fellows & $36(19.0 \%)$ & $404(6.6 \%)$ & $440(7.0 \%)$ & $<.001$ \\
\hline
\end{tabular}

reasons FPs who provide abortions are more likely to work at academic institutions is because these organizations are motivated to break down institutional barriers to integrate abortion into the teaching curriculum. ${ }^{29}$ While FPs who provide abortion care are more likely to provide continuity care compared to FPs who do not provide abortion care, we cannot determine if this abortion provision is occurring within their primary care settings.

Regional differences between abortion providers and other recent graduates show that FPs providing abortions more commonly completed residency in the Northeast and the West but practice in the South and the West. When looking at national data from family medicine residencies with integrated abortion training, $52 \%$ of residents graduated from programs in the Northeast, $43 \%$ from programs in the West, and only $5 \%$ from Midwestern programs. ${ }^{28}$ In this study, respondents who received abortion training were more evenly distributed, with $35.1 \%$ of respondents graduating from programs in the West, $25.5 \%$ in the Northeast, $21.8 \%$ in the Midwest, and $17.5 \%$ in the South. No residency programs in the South report having integrated abortion training. However, $17.5 \%$ of respondents in this study received residency training in the South, and $20.8 \%$ were providing abortions in the South 3 years after graduation. ${ }^{30}$ This finding may represent that FPs are more motivated to work in rural and underserved communities than other specialties like OB/GYN. ${ }^{31-33}$ FPs' commitment to underserved populations can fill 
the gap in nationwide abortion provision, especially where access to abortion is challenging.

While abortion is one of the most common procedures performed in the United States, abortion training is limited in family medicine residency and medical education. ${ }^{9,34}$ Resident physicians perceive abortion training to be beneficial for development of counseling and gynecologic procedural skills, ${ }^{35}$ as many reproductive health skills are additive in nature. This association between higher performance of SRH procedures and abortion care was supported by our finding. Abortion providers performed many other SRH procedures, including LARC insertion and removal; endometrial biopsy; maternity care and delivery services; uterine aspiration/D\&Cs; and colposcopy, at rates statistically significantly higher than their nonabortion-providing peers.

FPs demonstrate increasing comfort with integrating medication abortion into their practices. ${ }^{31}$ Therefore, it is not surprising that $40 \%$ of respondents who provided pregnancy terminations indicated they did not do "uterine aspiration/ D\&Cs," possibly signaling that they provide medication abortion only. A much larger number (294 respondents), indicated that they do provide uterine aspiration/D\&Cs, but a majority (64\%) of these same respondents reported that they do not provide pregnancy termination. This discrepancy between providing "uterine aspiration/D\&C's" and "pregnancy terminations" may be because physicians are providing miscarriage management and not abortion care, or they may have interpreted these categories to mean separate things. Since those physicians who perform uterine aspirations/D\&Cs have the skill set to perform abortions, it is unclear why they are not currently doing so. This divergence in practice is likely due to some of the commonly cited barriers to abortion provision, including institutional barriers, personal beliefs, insurance coverage, colleague support, and reimbursement for abortion servic$\mathrm{es},{ }^{35}$ and this is another area for future research.

\section{Limitations}

This study has several limitations. First, the data obtained are from a survey of FPs who completed residency between 2013 and 2015; it is a sample of clinicians early in their careers and may not be generalizable to all FPs. Racial and ethnic demographic information was not available for all of our cohorts, making it difficult to compare this characteristic for those who provide pregnancy termination and those who do not. However, starting in 2017, racial and ethnic demographic information was asked in the exam registration questionnaire and will be available for samples moving forward. Another limitation relates to missing data for certain survey variables, because respondents were not required to answer every question; thus the denominator is not consistent for each data point. Though secondary sites of practice were collected, this data did not clarify if FPs who provide abortions are doing so in their primary care settings. It is possible that this excluded FPs who provide abortion outside of their primary care setting or in other states. Finally, questions and language used in the survey instrument about "pregnancy termination" and "uterine aspiration" did not differentiate whether respondents were offering medication abortion, procedural abortion, or both. While "termination of pregnancy" is commonly used in medical literature, this word choice is often selected under the incorrect assumption that using the word "abortion" causes distress. However, research has shown that the word "abortion" is a more widely used term, is not distressing, and allows for clearer understanding than "termination of pregnancy." ${ }^{36-38}$

\section{Conclusions}

First trimester abortion is safe, common, and within the scope of practice for FPs; nonetheless, abortion provision by FPs remains low. Among
FPs who participated in this survey, $13 \%$ reported that their residency prepared them to provide pregnancy termination and only $3 \%$ reported providing pregnancy termination in their practice. Most of those who provide pregnancy termination completed residency training in the Northeast or the West, provide continuity care, and practice in geographically diverse locations, mostly in the Western or Southern United States. Clinicians who provide pregnancy termination are more likely to provide other SRH procedures and are more likely to teach students, residents, or fellows. Future studies are needed to further characterize FPs who provide abortion services on a larger scale extending beyond the recent graduates described in this study. This can provide more insight into where these FPs received abortion training, where they are practicing now, if they are providing abortions in their primary care practice or multiple locations, and what type of abortions they are providing for their patients. Learning more about this population of providers will provide guidance for future interventions to expand abortion access and training and to improve care for all pregnant patients in the United States.

ACKNOWLEDGMENTS: The authors acknowledge the efforts of Adriana Marquina, MPH, and Zoey Thill MD, MPP, MPH, for their factual review of this manuscript and their editing input.

CORRESPONDING AUTHOR: Address correspondence to Dr Marji Gold, Montefiore Medical Center, 3544 Jerome Avenue, Bronx NY 10467. 718 920-4678. Fax: 212-366-9321. marji.gold@einsteinmed.org.

FUNDING STATEMENT: This project was supported by the visiting scholars program at the American Board of Family Medicine.

PRESENTATIONS: Demographic data from this data set was presented as a poster at the NAPCRG works-in-progress session, November 16, 2019 in Toronto, Ontario, Canada.

\section{References}

1. National Academies of Sciences, Engineering, and Medicine. The Safety and Quality of Abortion Care in the United States. Washington, DC: The National Academies Press; 2018. 
2. Jones RK, Witwer E and Jerman J, Abortion Incidence and Service Availability in the United States, 2017, New York: Guttmacher Institute; 2019. https://doi.org/10.1363/2019.30760

3. Cartwright AF, Karunaratne M, Barr-Walker J, Johns NE, Upadhyay UD. Identifying National Availability of Abortion Care and Distance From Major US Cities: Systematic Online Search. J Med Internet Res. 2018;20(5):e186.

4. Fink KS, Phillips RL Jr, Fryer GE, Koehn N. International medical graduates and the primary care workforce for rural underserved areas. Health Aff (Millwood). 2003;22(2):255262.

5. Fryer GE, Green LA, Dovey SM, Phillips RI Jr. The United States relies on family physicians unlike any other specialty. Am Fam Physician. 2001;63(9):1669.

6. Phillips R, Dodoo M, Petterson S, et al. Specialty and Geography distribution of the physician workforce: what influences medical student and resident choices?. Washington, DC: The Robert Graham Center; 2009.

7. Ruddy G, Fryer E, Phillips R, Green L, Dodoo M, McCann J. The family physician workforce: the special case of rural populations. Am Fam Physician. 2005;72(1):147.

8. Herbitter C, Bennett A, Schubert FD, Bennett IM, Gold M. Management of early pregnancy failure and induced abortion by family medicine educators. J Am Board Fam Med. 2013;26(6):751-758.

9. Herbitter C, Greenberg M, Fletcher J, Query C, Dalby J, Gold M. Family planning training in US family medicine residencies. Fam Med. 2011;43(8):574-581.

10. Altshuler AL, Ojanen-Goldsmith A, Blumenthal PD, Freedman LR. A good abortion experience: A qualitative exploration of women's needs and preferences in clinical care. Soc Sci Med. 2017;191:109-116.

11. Foster DG, Kimport K, Gould H, Roberts SC, Weitz TA. Effect of abortion protesters on women's emotional response to abortion. Contraception. 2013;87(1):81-87.

12. Godfrey EM, Rubin SE, Smith EJ, Khare MM, Gold M. Women's preference for receiving abortion in primary care settings. J Womens Health (Larchmt). 2010;19(3):547-553.

13. Kimport K, Cockrill K, Weitz TA. Analyzing the impacts of abortion clinic structures and processes: a qualitative analysis of women's negative experience of abortion clinics. Contraception. 2012;85(2):204-210

14. Logsdon MB, Handler A, Godfrey EM. Women's preferences for the location of abortion services: a pilot study in two Chicago clinics. Matern Child Health J. 2012;16(1):212-216.
15. McLemore MR, Desai S, Freedman L, James EA, Taylor D. Women know best-findings from a thematic analysis of 5,214 surveys of abortion care experience. Womens Health Issues. 2014;24(6):594-599

16. Page C, Stumbar S, Gold M. Attitudes and preferences toward the provision of medication abortion in an urban academic internal medicine practice. J Gen Intern Med. 2012;27(6):647-652.

17. Rubin SE, Godfrey E, Gold M. Patient attitudes toward early abortion services in the family medicine clinic. J Am Board Fam Med. 2008;21(2):162-164

18. Rubin SE, Godfrey EM, Shapiro M, Gold M. Urban female patients' perceptions of the family medicine clinic as a site for abortion care. Contraception. 2009;80(2):174-179.

19. Shochet T, Trussell J. Determinants of demand: method selection and provider preference among US women seeking abortion services. Contraception. 2008;77(6):397-404.

20. Wu JP, Godfrey EM, Prine L, Andersen KL, MacNaughton H, Gold M. Women's satisfaction with abortion care in academic family medicine centers. Fam Med. 2015;47(2):98-106.

21. Espey E, Leeman L, Ogburn T, Skipper B, Eyman C, North M. Has mifepristone medical abortion expanded abortion access in New Mexico? A survey of OB-GYN and Family Medicine physicians. Contraception. 2011;84(2):178183.

22. Freedman L. Willing and Unable: Doctors' Constraints in Abortion Care. Nashville, TN: Vanderbilt University Press; 2012.

23. Goodman S, Shih G, Hawkins M, et al. A longterm evaluation of a required reproductive health training rotation with opt-out provisions for family medicine residents. Fam Med. 2013;45(3):180-186.

24. Greenberg M, Herbitter C, Gawinski BA Fletcher J, Gold M. Barriers and enablers to becoming abortion providers: the reproductive health program. Fam Med. 2012;44(7):493-500.

25. Steinauer J, Landy U, Filippone H, Laube D, Darney PD, Jackson RA. Predictors of abortion provision among practicing obstetriciangynecologists: a national survey. Am J Obstet Gynecol. 2008;198(1):39.e1-39.e6.

26. Kendall MC, Hansen ER, Peterson LE. Re: Burnout in Young Family Physicians: Variation Across States. J Am Board Fam Med. 2018;31(4):663

27. Weidner AKH, Chen FM, Peterson LE. Developing the National Family Medicine Graduate Survey. J Grad Med Educ. 2017;9(5):570-573.
28. Stulberg DB, Monast K, Dahlquist IH, Palmer K. Provision of abortion and other reproductive health services among former Midwest Access Project trainees. Contraception. 2018;97(4):341345

29. Summit A, Lague I, Dettman M, Gold M. Barriers and enablers to abortion provision for family physicians trained in abortion during residency. 2020

30. Romero D, Maldonado L, Fuentes L, Prine L. Association of reproductive health training on intention to provide services after residency: the family physician resident survey. Fam Med. 2015;47(1):22-30.

31. Petterson S, McNellis R, Klink K, Meyers D, Bazemore A. The State of Primary Care in the United States: A Chartbook of Facts and Statistics. Washington, DC: The Robert Graham Center; 2018.

32. Ruddy G, Fryer E, Green L, Dodoo M, McCann J. The family physician workforce: the special case of rural populations. Am Fam Physician. 2005;72(1):147.

33. Committee on Health Care for Underserved Women. ACOG Committee opinion no. 612: abortion training and education. Obstet Gynecol. 2014;124(5):1055-1059.

34. Espey E, Ogburn T, Chavez A, Qualls C, Leyba M. Abortion education in medical schools: a national survey. Am J Obstet Gynecol. 2005;192(2):640-643.

35. Greenberg S, Nothnagle M. An "Invaluable Skill": Reflections on Abortion Training and Postresidency Practice. Fam Med. 2018;50(9):691-693.

36. Cameron S, Lohr PA, Ingham R. Abortion terminology: views of women seeking abortion in Britain. J Fam Plann Reprod Health Care. 2017;43(4):265-268.

37. Chien P. Termination of pregnancy or abortion? BJOG. 2018;125(11):1345-1345.

38. Grimes DA, Stuart G. Abortion jabberwocky: the need for better terminology. Contraception. 2010;81(2):93-96. 